\title{
Parietal Layer of Bowman Capsule
}

National Cancer Institute

\section{Source}

National Cancer Institute. Parietal Layer of Bowman Capsule. NCI Thesaurus. Code C33271.

The outermost layer of the renal capsule, which is composed of a single layer of simple squamous epithelium. 